\title{
Comportamento ingestivo de ovinos e digestibilidade aparente dos nutrientes de dietas contendo casca de soja
}

\author{
Janice Barreto de Morais( ${ }^{(1)}$, Ivanete Susin(1), Alexandre Vaz Pires ${ }^{(1)}$, Clayton Quirino Mendes ${ }^{(1)}$, \\ Reinaldo Cunha de Oliveira Junior ${ }^{(1)}$ e Irineu Umberto Packer ${ }^{(1)}$
}

\begin{abstract}
(1)Escola Superior de Agricultura Luiz de Queiroz, Dep. de Zootecnia, Av. Pádua Dias, no 11, Caixa Postal 9. CEP 13418-900 Piracicaba, SP. E-mail: janmorais2001@yahoo.com.br, ivasusin@esalq.usp.br, alvpires@esalq.usp.br, cqmendes@esalq.usp.br, reinaldocoj@yahoo.com.br, iupacker@esalq.usp.br
\end{abstract}

Resumo - Dois experimentos foram realizados para avaliar os efeitos da substituição do feno de coastcross por casca de soja, sobre o comportamento ingestivo e sobre a digestibilidade dos nutrientes no trato digestório total de ovinos. No primeiro experimento, 48 borregas, com peso inicial médio de 23,1 kg e 124 dias de idade foram distribuídas em blocos completamente ao acaso. O tratamento controle foi composto por feno de coastcross e concentrado (50:50). Nos demais, a casca de soja substituiu o feno em 12,5, 25 e 37,5\% da matéria seca (MS) da dieta. Tempos de ingestão e ruminação foram determinados a cada cinco minutos durante 24 horas. Houve efeito linear decrescente no comportamento ingestivo, à medida que se aumentou a casca de soja na dieta. No segundo experimento, quatro borregos foram distribuídos em quadrado latino $4 \times 4$ e submetidos aos mesmos tratamentos do primeiro experimento. Houve efeito linear crescente da casca de soja sobre o consumo e digestibilidade da MS, da matéria orgânica (MO), da fibra em detergente neutro (FDN) e da hemicelulose, e sobre o consumo da fibra em detergente ácido. A casca de soja possui menor quantidade de FDN fisicamente efetiva, em comparação à FDN de feno de coastcross e, ao ser adicionada em dietas para borregas até $37,5 \%$ da MS, aumenta a digestibilidade da MS e da MO.

Termos para indexação: fibra em detergente neutro, FDN fisicamente efetiva, valor nutritivo.

\section{Ingestive behavior of sheep and nutrients digestibility of diet containing soybean hulls}

\begin{abstract}
Two trials were performed to evaluate the effects of replacing coastcross hay by soybean hulls on ewe lambs ingestive behavior and diet digestibility. In the first trial, forty-eight ewe lambs (23.1 kg initial BW and 124 days old) were assigned to a randomized block design. The control diet contained $50 \%$ coarsely chopped coastcross hay and no soybean hulls. In the remaining treatments, soybean hulls replaced hay by $12.5 \%, 25 \%$ or $37.5 \%$ on dry matter (DM) basis. Eating and ruminating times were determined every five min during 24 hours. There was a decreased linear effect for ingestive (eating, ruminating and total chewing) behavior as soybean hulls were added to the diet. In the second trial, four Santa Ines ram lambs were arranged in a $4 \times 4$ latin square design and fed the same treatments as in the first trial. There was an increased linear effect of soybean hulls on $\mathrm{DM}$, organic matter (OM), NDF and hemicellulose intake and digestibilities. ADF intake also increased linearly. Soybean hulls contains lower NDF physical effectiveness as compared to coastcross hay and its addition up to $37.5 \%$ of the diet DM improved OM and DM digestibilities.
\end{abstract}

Index terms: neutral detergent fiber, NDF physical effectiveness, nutritive value.

\section{Introdução}

Em razão do alto custo de produção de forragens conservadas (feno e silagem), subprodutos da indústria alimentícia estão sendo estudados na alimentação de ruminantes sob o ponto de vista econômico e nutricional. A casca de soja, subproduto das indústrias de processamento da soja, surgiu como fonte alternativa, que contribui para o valor da fibra, na formulação de dietas para ruminantes (Armentano \& Pereira, 1997).
Em determinadas regiões do Brasil, a casca de soja apresenta grande disponibilidade no mercado e, na maioria dos casos, sua inclusão na formulação de dietas para ruminantes reduz o custo de produção.

A casca de soja é definida como um volumoso-concentrado, pois, tem a função fisiológica de fibra vegetal e funciona como um grão de cereal em termos de disponibilidade de energia (3,01 Mcal energia digestível por quilograma de matéria seca) (National Research Council, 2001). Ipharraguerre \& Clark (2003) compilaram tra- 
balhos sobre a composição química da casca de soja e encontraram valores médios de $11,8 \%$ de proteína bruta e 65,6\% de fibra em detergente neutro (FDN) na matéria seca (MS), sendo 43\% composta de celulose e 17,8\% de hemicelulose.

A casca de soja usada como suplemento em dietas à base de forragens (Royes et al., 2001), ou a substituição parcial de forragens pela casca de soja (Silva et al., 2002), pode aumentar a digestibilidade da FDN da dieta. Esse fator estaria relacionado com a própria natureza da fibra da casca e com a redução dos efeitos negativos associativos, que ocorrem na digestão da fibra da forragem, quando o milho é utilizado (Firkins, 1997). Garcés-Yépez et al. (1997) observaram aumento na digestibilidade da FDN da dieta, quando elevaram a quantidade de casca de soja de 20 para $40 \%$ da MS, em dietas com altas proporções de forragem (80 a 60\% da MS, respectivamente). Isto não ocorreu quando o milho foi acrescentado no mesmo teor. Os autores sugeriram que a casca de soja não interferiu negativamente na atividade de bactérias celulolíticas do rúmen, como o milho interferiu, resultando no decréscimo da digestibilidade da fibra da forragem.

Embora o teor de FDN da casca de soja seja semelhante ao de forragens, seu estímulo à mastigação é restrito, devido ao tamanho reduzido das partículas. Quando a mastigação do alimento é limitada, ocorre redução da produção de saliva, podendo levar à diminuição do pH ruminal e, conseqüentemente, da digestibilidade da fibra. A fim de minimizar esse processo, recomenda-se adicionar quantidade mínima de forragem, observando tamanho adequado de partícula da dieta, para reduzir a taxa de passagem do alimento, estimular a atividade de mastigação e promover uma digestão mais completa da fibra proveniente de subprodutos (Grant, 1997).

O objetivo deste trabalho foi avaliar os efeitos da substituição do feno de coastcross (Cynodon sp.) por casca de soja, sobre o comportamento ingestivo (ruminação, ingestão e mastigação), o consumo e a digestibilidade dos nutrientes no trato digestório total de ovinos Santa Inês.

\section{Material e Métodos}

Para avaliar o comportamento ingestivo de ovinos, realizou-se um experimento no Departamento de Zootecnia da Escola Superior de Agricultura Luiz de Queiroz. Foram utilizadas 48 borregas da raça Santa Inês, com peso médio inicial de 23,13 $\pm 3,30$ kg e idade média inicial de $124 \pm 9$ dias. As borregas foram confinadas em baias cobertas, com piso de concreto, cocho e bebedouros, sendo distribuídos dois animais por baia e seis baias por tratamento.

Os animais foram vacinados contra clostridioses antes da desmama e tratados contra vermes antes do início do experimento. A verminose ou coccidiose foi avaliada em exames de fezes, quinzenais, para contagem de ovos por grama de fezes (OPG) e controlada quando necessário.

O período experimental foi de 84 dias, dividido em três subperíodos de 28 dias de duração. No 26o dia de cada subperíodo experimental, foi avaliado o comportamento ingestivo de todos os animais, individualmente, durante 24 horas, com observações a cada cinco minutos (Weidner \& Grant, 1994a, 1994b; Abel-Caines et al., 1997), para determinar o tempo empregado na ingestão e ruminação em minutos por dia. O tempo total de cada atividade foi calculado, multiplicando-se o número total de observações por cinco. A atividade de mastigação foi calculada pela soma das atividades de ingestão e ruminação, conforme Armentano \& Pereira (1997). As atividades de ruminação, ingestão e mastigação foram expressas em minutos por dia, minutos por grama de MS e minutos por grama de FDN consumida. Também foram consideradas na análise as observações feitas a cada 10 e 15 minutos. Foram realizados cálculos utilizando os dados obtidos a cada cinco minutos, a fim de avaliar a precisão das observações, quando são registradas em intervalos maiores do que cinco minutos. As rações foram fornecidas pela manhã, antes do início da avaliação do comportamento ingestivo.

Foram realizados quatro tratamentos experimentais: 0 (0CS); 12,5 (12,5CS); 25 (25CS) e 37,5\% (37,5CS) de inclusão de casca de soja (CS) na dieta, de forma que a casca de soja substituiu 0, 25, 50 e 75\% da FDN do feno na dieta. Multiplicou-se a FDN proveniente do feno na dieta 0CS por 0,25, 0,5 e 0,75 para obter a FDN oriunda da casca de soja nas dietas 12,5CS, 25CS e $37,5 \mathrm{CS}$, respectivamente. As dietas continham, aproximadamente, os mesmos valores de proteína bruta e FDN. Os teores de FDN e PB (\% MS) obtidos pela análise bromatológica do feno e da casca de soja foram de 72,8 e $11,4 \%$ e 73,3 e $9,4 \%$, respectivamente. Para obter a composição química das dietas, os concentrados e o feno foram analisados separadamente. A proporção dos ingredientes e a composição química das dietas estão descritas na Tabela 1. 
O feno foi processado duas vezes, em uma desintegradora, antes do fornecimento aos animais, e o alimento concentrado foi misturado previamente em um misturador horizontal (capacidade de $500 \mathrm{~kg}$ ) e armazenado em tambores de plástico de $200 \mathrm{~L}$. O feno e o concentrado foram pesados separadamente e misturados nos cochos no momento do fornecimento.

As dietas foram fornecidas ad libitum, uma vez ao dia, às 8h, e as sobras registradas diariamente, para determinação do consumo diário de matéria seca por baia. As sobras foram amostradas semanalmente por baia experimental, conservadas a $-10^{\circ} \mathrm{C}$ e, posteriormente, descongeladas e secadas em estufas de ventilação forçada $\left(55-60^{\circ} \mathrm{C}\right)$, de acordo com Goering \& Van Soest (1970), para determinação da matéria seca.

As amostras de alimento oferecido e recusado foram moídas em moinhos tipo Wiley, providos de peneiras com crivos de $1 \mathrm{~mm}$ e analisadas quanto à MS e matéria mineral (MM) de acordo com a Association of Official Analytical Chemists (1990), e FDN, utilizando amilase e sulfito de sódio conforme Van Soest et al. (1991). A matéria orgânica foi calculada pela diferença entre a matéria seca e a matéria mineral. Foram determinados os teores de PB, conforme a Association of Official Analytical Chemists (1990), e FDA, segundo Goering \& Van Soest et al. (1970), somente nas amostras do alimento oferecido. A hemicelulose foi calculada pela

Tabela 1. Proporção dos ingredientes e composição química das dietas experimentais (\% MS).

\begin{tabular}{|c|c|c|c|c|}
\hline \multirow[t]{2}{*}{ Ingredientes } & \multicolumn{4}{|c|}{ Tratamentos $^{(1)}$} \\
\hline & $0 \mathrm{CS}$ & $12,5 \mathrm{CS}$ & $25 \mathrm{CS}$ & $37,5 \mathrm{CS}$ \\
\hline Milho & 34,6 & 33,8 & 32,9 & 32,1 \\
\hline Farelo de soja & 13,2 & 14,0 & 14,7 & 15,4 \\
\hline Mistura mineral $^{(2)}$ & 2,1 & 2,0 & 2,0 & 2,0 \\
\hline Feno de coastcross & 50,1 & 37,6 & 25,0 & 12,5 \\
\hline Casca de soja & - & 12,6 & 25,4 & 38,0 \\
\hline \multicolumn{5}{|l|}{ Composição química } \\
\hline Proteína bruta & 15,7 & 16,2 & 15,9 & 15,1 \\
\hline Matéria mineral & 6,5 & 6,3 & 5,5 & 5,4 \\
\hline Fibra em detergente ácido & 20,5 & 22,3 & 23,3 & 27,0 \\
\hline Fibra em detergente neutro & 42,7 & 43,8 & 43,1 & 44,0 \\
\hline $\mathrm{FDNf}^{(3)}$ & 36,5 & 27,4 & 18,2 & 9,1 \\
\hline $\mathrm{FDNcs}^{(4)}$ & - & 9,2 & 18,6 & 27,8 \\
\hline FDNf $(\% \text { FDN total })^{(5)}$ & 85,5 & 62,6 & 42,2 & 20,7 \\
\hline Hemicelulose & 22,2 & 21,5 & 19,8 & 17,0 \\
\hline
\end{tabular}

(1)0CS: sem inclusão de casca de soja; 12,5CS, 25CS e 37,5CS: 12,5, 25 e $37,5 \%$ de inclusão de casca de soja, respectivamente. (2)Composição: 7,5\% de P; $19 \%$ de Ca; $1 \%$ de $\mathrm{Mg} ; 7 \%$ de S; $14,3 \%$ de Na; $21,8 \%$ de $\mathrm{Cl}$; 500 ppm de Fe; 300 ppm de Cu; 4.600 ppm de Zn; 1.100 ppm de Mn; 80 ppm de I; 405 ppm de Co; 30 ppm de Se. ${ }^{(3)} F D N f$ fibra detergente neutro oriunda da forragem. ${ }^{(4)} \mathrm{FDNcs}$ : fibra detergente neutro oriunda da casca de soja. ${ }^{(5)}$ FDNf (\%FDN total): porcentagem da FDN da forragem em relação a FDN total da dieta. diferença entre teores de FDN e de fibra em detergente ácido (FDA) das dietas oferecidas.

O delineamento experimental foi o de blocos completamente ao acaso, com quatro tratamentos e seis repetições. As variáveis determinadas no comportamento ingestivo foram: tempos de ingestão e de ruminação e atividade de mastigação (em minutos por dia, minutos por grama de MS e minutos por grama de FDN ingerida). $\mathrm{Na}$ avaliação do comportamento ingestivo, as atividades de ingestão e ruminação (em minutos por dia) foram analisadas nos intervalos de observação de 5, 10 e 15 minutos. Todos os dados foram analisados pelo procedimento MIXED do SAS (SAS Institute, 1996), envolvendo os efeitos fixos de tratamento, subperíodo e tempo (5, 10 e 15 minutos - apenas na avaliação da metodologia) e suas interações. As médias foram obtidas pelo comando LSMEANS. Utilizaram-se polinômios ortogonais (efeito linear e quadrático) nas variáveis com respostas significativas.

A fim de avaliar o consumo e a digestibilidade dos nutrientes no trato digestório total, quatro borregos da raça Santa Inês, com peso médio inicial de $43,1 \mathrm{~kg}$ e idade média de nove meses, foram distribuídos em um delineamento de quadrado latino $4 \times 4$ e alojados em gaiolas metálicas individuais, com dimensões de 1,3x0,55 m, providas de cocho e bebedouro, para ensaios de metabolismo.

As dietas foram as mesmas utilizadas no primeiro experimento (Tabela 1) com fornecimento ad libitum, uma vez ao dia, às $8 \mathrm{~h}$. O período experimental teve duração de 56 dias com quatro subperíodos de 14 dias cada, sendo dez dias de adaptação dos animais às dieta e quatro dias para a coleta de dados e amostras. Os animais foram pesados no início de cada período, e no primeiro e último dia de cada subperíodo de coleta.

Dados de consumo de MS por animal por dia foram obtidos por meio da diferença entre a quantidade de alimento fornecida e a recusada. As sobras de alimento e as fezes foram coletadas totalmente, uma vez ao dia (nos quatro dias de coleta), compostas por animal e período e congeladas a $-10^{\circ} \mathrm{C}$. As fezes foram amostradas em uma alíquota de $10 \%$ do total. Posteriormente, as amostras do alimento oferecido, do recusado e das fezes foram descongeladas, compostas por animal e período e, secadas em estufa de ventilação forçada $\left(55-60^{\circ} \mathrm{C}\right)$, por 72 horas, de acordo com Goering \& Van Soest (1970).

Todas as amostras foram moídas em moinhos tipo Wiley, providos de peneira com crivos de $1 \mathrm{~mm}$, e analisadas quanto à MS e matéria mineral (MM), conforme 
Association of Official Analytical Chemists (1990), FDN, segundo Van Soest et al. (1991), e FDA, conforme Goering \& Van Soest (1970). A matéria orgânica das amostras foi calculada pela diferença entre a matéria seca e a matéria mineral. A hemicelulose foi obtida por meio da diferença entre a FDN e a FDA das dietas. A digestibilidade aparente dos nutrientes (DAN) foi calculada da seguinte forma:

DAN $=100[($ MSC $x$ NMS $)-($ MSF $x$ NMF $)] /($ MSC $x$ NMS)

em que MSC é a matéria seca consumida; MSF é a matéria seca fecal; NMF é a porcentagem do nutriente na matéria seca fecal; NMS é a porcentagem do nutriente na matéria seca consumida.

Os dados foram analisados pelo procedimento GLM do SAS (SAS Institute, 1996). As médias foram obtidas pelo comando LSMEANS. Nos casos com respostas significativas, foi aplicado teste de polinômios ortogonais (efeito linear e quadrático).

\section{Resultados e Discussão}

Os dados relativos aos tempos empregados com ingestão, ruminação e mastigação, expressos em minutos por dia, minutos por grama de MS e minutos por grama de FDN estão descritos na Tabela 2.

Houve efeito linear decrescente quanto a todos os tempos de ingestão em minutos por dia $(y=-9,0139 \mathrm{x}+$ 270,$\left.14 ; R^{2}=0,03\right)$, em minutos por grama de MS $\left(y=-0,0263 x+0,3031 ; R^{2}=0,22\right)$ e minutos por grama de FDN ( $\left.y=-0,0855 x+0,7969 ; R^{2}=0,34\right)$; de ruminação em minutos por dia $(\mathrm{y}=-34,069 \mathrm{x}+451,04$; $\left.\mathrm{R}^{2}=0,30\right)$, em minutos por grama de MS $(\mathrm{y}=-0,0585 \mathrm{x}$ $\left.+0,4981 ; \mathrm{R}^{2}=0,51\right)$ e minutos por grama de FDN $\left(y=-0,1713 x+1,2975 ; R^{2}=0,60\right) ;$ e de mastigação em minutos por dia $\left(\mathrm{y}=-43,083 \mathrm{x}+721,18\right.$; $\left.\mathrm{R}^{2}=0,27\right)$, minutos por grama de MS $(y=-0,0853 x+0,8032$; $\left.\mathrm{R}^{2}=0,51\right)$ e minutos por grama de FDN $(\mathrm{y}=-0,257 \mathrm{x}+$ 2,0953; $\mathrm{R}^{2}=0,63$ ), os quais reduziram à medida que $\mathrm{a}$ casca de soja foi adicionada à dieta (Tabela 2).

A redução do tamanho de partícula das dietas com a inclusão da casca foi um dos fatores que contribuiu para esses resultados. O tempo de mastigação em minutos por dia, minutos por grama de MS e minutos por grama de FDN na dieta 37,5CS foi 20, 37 e $45 \%$ menor do que na dieta 0CS, respectivamente.

Fimbres et al. (2002) trabalharam com teores crescentes de feno na alimentação de ovinos (0, 10, 20 e $30 \%$ da MS) e observaram um efeito linear crescente no tempo de ingestão, ruminação e mastigação em minutos por dia, com o aumento da quantidade de feno na dieta. O tempo de ruminação, com $10 \%$ de feno (308 minutos por dia), foi próximo ao da dieta com 12,5\% de feno (289 minutos por dia) (Tabela 2).

A dieta com $25 \%$ de casca de soja e $25 \%$ de feno apresentou valores próximos de ruminação e mastigação, em minutos por dia, aos da dieta controle utilizada por Weidner \& Grant (1994a), que continha 27,5\% de FDN total e $60 \%$ de forragem, sem casca de soja. Isso mostra que a dieta $25 \mathrm{CS}$, que continha $25 \%$ de feno (Tabela 2), ainda manteve um tempo satisfatório de ruminação e de mastigação, quando comparado ao estudo destes autores. Porém, as dietas neste experimento possuíam 16,5 pontos porcentuais a mais de FDN do que a dieta utilizada por Weidner \& Grant (1994a).

O tempo de ruminação no tratamento 25CS (381 minutos por dia) (Tabela 2) também foi próximo ao observado por Weidner \& Grant (1994a), quando utilizaram dieta com $25 \%$ de casca de soja e $20 \%$ de feno de alfafa (375 minutos por dia). Neste último, a adição do feno

Tabela 2. Efeito da inclusão da casca de soja na dieta sobre o comportamento ingestivo de borregas confinadas.

\begin{tabular}{|c|c|c|c|c|c|c|c|}
\hline \multirow[t]{2}{*}{ Itens $^{(1)}$} & \multicolumn{4}{|c|}{ Tratamentos ${ }^{(2)}$} & \multirow[t]{2}{*}{$\mathrm{EPM}^{(3)}$} & \multicolumn{2}{|c|}{$\mathrm{P}^{(4)}$} \\
\hline & $0 \mathrm{CS}$ & $12,5 \mathrm{CS}$ & $25 \mathrm{CS}$ & $37,5 \mathrm{CS}$ & & Linear & Quadrático \\
\hline \multicolumn{8}{|l|}{ Ingestão } \\
\hline Min. dia ${ }^{-1}$ & 261 & 255 & 237 & 237 & 12,97 & 0,0141 & 0,7386 \\
\hline Min. $\mathrm{g}^{-1}$ de MS & 0,28 & 0,25 & 0,22 & 0,20 & 0,013 & $<0,0001$ & 0,8381 \\
\hline Min. $g^{-1}$ de FDN & 0,71 & 0,62 & 0,54 & 0,46 & 0,019 & $<0,0001$ & 0,7294 \\
\hline \multicolumn{8}{|l|}{ Ruminação } \\
\hline Min. dia ${ }^{-1}$ & 398 & 395 & 381 & 289 & 10,43 & $<0,0001$ & $<0,005$ \\
\hline Min. $\mathrm{g}^{-1}$ de MS & 0,42 & 0,39 & 0,35 & 0,24 & 0,012 & $<0,0001$ & $<0,005$ \\
\hline Min. $\mathrm{g}^{-1}$ de FDN & 1,09 & 0,96 & 0,87 & 0,55 & 0,024 & $<0,0001$ & $<0,005$ \\
\hline \multicolumn{8}{|l|}{ Mastigação } \\
\hline Min. dia ${ }^{-1}$ & 658 & 650 & 619 & 526 & 14,19 & $<0,0001$ & $<0,005$ \\
\hline Min. $\mathrm{g}^{-1}$ de MS & 0,70 & 0,65 & 0,57 & 0,44 & 0,017 & $<0,0001$ & $<0,005$ \\
\hline Min. $\mathrm{g}^{-1}$ de FDN & 1,81 & 1,59 & 1,40 & 1,00 & 0,046 & $<0,0001$ & $<0,005$ \\
\hline
\end{tabular}

${ }^{(1)}$ Tempos de ingestão, ruminação e mastigação em minutos por dia, minutos por grama de MS ou minutos por grama de FDN consumida. (2)0CS: sem inclusão de casca de soja; 12,5CS, 25CS e 37,5CS: 12,5, 25 e 37,5\% de inclusão de casca de soja, respectivamente. (3)Erro-padrão da média. (4)Probabilidade de efeito (linear ou quadrático) dos tratamentos sobre as variáveis. 
aumentou o tamanho de partícula da dieta, o consumo de FDN, a atividade de ruminação, o pH ruminal e a relação acetato:propionato, quando comparado ao tratamento com casca e sem feno. Isso comprova as conclusões de Grant (1997), segundo as quais, quando fontes de fibra não-forragem substituem parcialmente uma forragem, é necessário que o tamanho de partícula da forragem seja suficiente para estimular a ruminação, evitar a redução do pH e reter por mais tempo as partículas menores no rúmen.

A FDN fisicamente efetiva (FDNfe) da casca de soja - fração da fibra que estimula a mastigação - é menor do que a FDNfe proveniente de uma fonte de forragem (Grant, 1997). Sua inclusão reduz a atividade de mastigação, porém, pode aumentar o consumo de FDN por unidade de mastigação. Isso foi confirmado por Weidner \& Grant (1994b), quando aumentaram a substituição das silagens de milho e de alfafa por casca de soja, de $25 \%$ para $42 \%$, e obtiveram redução na atividade de mastigação em $31 \%$, mas o consumo de FDN por minuto de mastigação aumentou de 11 para 16 g. Neste estudo, houve aumento no consumo de 0,55 para $1 \mathrm{~g}$ de FDN por minuto nas dietas 0CS e 37,5CS, respectivamente (Tabela 2 ).

Apesar de a adição da casca de soja ocasionar redução na atividade de mastigação, a quantidade de fibra potencialmente digestível é um fator que compensa a menor produção de saliva, pois promove padrão de fermentação semelhante ao de forragem, contribuindo, desta forma, para manter o $\mathrm{pH}$ ruminal e não prejudicar a digestibilidade dos nutrientes, como foi constatado neste trabalho.

Valores referentes aos tempos de observação dos animais, a cada 10 e 15 minutos, na avaliação do comportamento ingestivo, estão descritos na Tabela 3. Não

Tabela 3. Comparação dos tempos de observação dos animais (a cada 5, 10 ou 15 minutos durante 24 horas), na avaliação do comportamento ingestivo.

\begin{tabular}{|c|c|c|c|c|c|}
\hline \multirow{2}{*}{$\begin{array}{l}\text { Tempo de } \\
\text { observação (min) }\end{array}$} & \multicolumn{4}{|c|}{ Tratamentos $^{(1)}$} & \multirow[t]{2}{*}{ Média } \\
\hline & $0 \mathrm{CS}$ & $12,5 \mathrm{CS}$ & $25 \mathrm{CS}$ & $37,5 \mathrm{CS}$ & \\
\hline & \multicolumn{5}{|c|}{ Ruminação (minutos pordia) ${ }^{(2)}$} \\
\hline 5 & 398 & 395 & 381 & 289 & 366 \\
\hline 10 & 398 & 396 & 389 & 289 & 368 \\
\hline 15 & 398 & 399 & 386 & 287 & 367 \\
\hline \multirow[t]{2}{*}{ Média } & 398 & 397 & 385 & 289 & \\
\hline & \multicolumn{5}{|c|}{ Ingestão (minutos por dia) ${ }^{(2)}$} \\
\hline 5 & 261 & 255 & 237 & 237 & 248 \\
\hline 10 & 260 & 260 & 234 & 242 & 249 \\
\hline 15 & 252 & 258 & 233 & 245 & 247 \\
\hline Média & 258 & 258 & 235 & 241 & \\
\hline
\end{tabular}

(1)0CS: sem inclusão de casca de soja; 12,5CS, 25CS e 37,5CS: 12,5, 25 e $37,5 \%$ de inclusão de casca de soja, respectivamente. (2)Não houve efeito de tempo de observação e da interação tempo de observação $x$ tratamento $(\mathrm{p}<0,05)$. houve efeito dos tempos de observação quanto às atividades de ruminação e ingestão em minutos por dia, bem como da interação tratamento x tempo de observação.

Trabalhos que avaliaram o comportamento ingestivo dos animais por meio de observações visuais (Weidner \& Grant, 1994a, 1994b; Abel-Caines et al., 1997; Rabelo, 2002) utilizaram o intervalo de cinco minutos, durante 24 horas, quanto aos tempos de ingestão e de ruminação que, posteriormente, foram somados, para obter a atividade de mastigação. Com este intervalo, admite-se que o animal permanece por cinco minutos realizando a mesma atividade (ingerindo, ruminando ou em ócio).

Teoricamente, quanto menor o intervalo de observação, menor será o risco de o animal mudar de atividade sem ser observado e, conseqüentemente, mais preciso será o resultado dos tempos de ruminação e ingestão. Entretanto, quando o número de observadores é escasso ou quando a quantidade de animais é grande, o intervalo de cinco minutos entre as observações pode ser curto para avaliar todos os animais, necessitando-se de maior espaço de tempo para tal avaliação.

Ao empregar-se maior intervalo de observação dos animais (10 ou 15 minutos), os resultados não foram diferentes do tempo comumente utilizado (cinco minutos), ou seja, o observador pode utilizar um intervalo de 10 ou 15 minutos entre uma observação e outra, quando mais conveniente ou necessário (Tabela 3). Esses dados estão de acordo com Silva et al. (2005), que compararam intervalos de observação de 5, 10, 15, 20, 25 e 30 minutos nas atividades de ingestão, ruminação e ócio em novilhas. Os autores não detectaram diferenças significativas entre os intervalos, sugerindo que o animal pode ser observado a cada 30 minutos sem comprometer os resultados.

Os dados de consumo e digestibilidade aparente da MS, da MO, da FDN, da FDA e da hemicelulose no trato digestório total de borregos estão descritos na Tabela 4. O consumo e a digestibilidade aparente no trato digestório total (DATT) da MS, da MO, da FDN e da hemicelulose aumentaram linearmente com a inclusão de casca de soja na dieta. Observou-se efeito linear no consumo e quadrático na DATT da FDA, com o aumento da casca de soja na dieta.

O aumento no consumo de matéria seca ( $\mathrm{y}=0,1154 \mathrm{x}$ $\left.+1,1093 ; R^{2}=0,22\right)$ e matéria orgânica ( $y=0,1168 x+$ 1,0196; $R^{2}=0,25$ ), com a inclusão de casca de soja na dieta ocorreu, provavelmente, em razão do tamanho reduzido de partículas da casca, havendo menor enchimento ruminal e maior taxa de passagem da dieta, fa- 
zendo com que o animal ingerisse mais alimento, à medida que a casca de soja era incluída ( 0 a 37,5\% na MS) e a quantidade de feno diminuía (50 a $12,5 \%$ na MS) nas dietas.

A inclusão de casca de soja proporcionou maior digestibilidade aparente da MS $(\mathrm{y}=1,5587 \mathrm{x}+71,765$; $\left.\mathrm{R}^{2}=0,39\right)$ e da $\mathrm{MO}\left(\mathrm{y}=1,4981 \mathrm{x}+73,118 ; \mathrm{R}^{2}=0,35\right)$ no trato digestório total, e os valores constatados foram superiores aos de autores que trabalharam para substituir feno de gramínea (Grigsby et al., 1992), milho (Ipharraguerre et al., 2002), ou utilizada como suplemento em dietas contendo feno de gramínea (Garcés-Yépez et al., 1997; Zervas et al., 1998; Royes et al., 2001) (Tabela 4).

Alguns autores também verificaram um aumento linear na digestibilidade da MS e/ou MO no trato digestório total, com a inclusão de casca de soja em dietas para bovinos de corte (Grigsby et al., 1992; Royes et al., 2001) ou para novilhas leiteiras (Trater et al., 2001). Silva et al. (2002) observaram aumento de 6,3\% na digestibilidade da MS no trato digestório total de bovinos, quando elevou a quantidade de casca de soja de 18 para $42 \%$ da MS da dieta, em substituição ao feno de coastcross.

Quando a casca de soja não substitui totalmente uma forragem, ou seja, quando há uma quantidade mínima de forragem na dieta, o tempo de retenção da casca no rúmen é maior, o que pode colaborar para melhor digestibilidade dos nutrientes presentes na casca. Isto foi observado por Nakamura \& Owen (1989), que trabalharam com vacas leiteiras e observaram aumento de $8 \%$ na taxa de passagem, quando a casca de soja passou de 25 para $48 \%$ da MS da dieta.

O aumento do consumo de FDN ( $\mathrm{y}=0,08 \mathrm{x}+0,4287$; $\left.\mathrm{R}^{2}=0,34\right)$, FDA $\left(\mathrm{y}=0,0467 \mathrm{x}+0,2177 ; \mathrm{R}^{2}=0,36\right) \mathrm{e}$ hemicelulose $\left(y=0,0338 x+0,21 ; R^{2}=0,29\right)$ deveu-se ao aumento do consumo de matéria seca, com a inclusão da casca de soja, já que as dietas apresentaram valores próximos de FDN entre si (Tabela 4). Weidner \& Grant (1994b) também constataram aumento do consumo de FDN, quando incluíram 15 e 25\% de casca de soja na dieta, em substituição à silagem de milho e alfafa, respectivamente.

A digestibilidade da FDN ( $\mathrm{y}=3,4823 \mathrm{x}+59,7$; $\left.\mathrm{R}^{2}=0,58\right)$ foi maior com a adição da casca de soja. A natureza da fibra desse subproduto pode ser um fator que contribuiu para esses resultados (Firkins, 1997), uma vez que a FDN da casca de soja mostrou ser mais digestível do que a FDN da forragem. Calculando-se a média dos três tratamentos com casca de soja, a digestibilidade da FDN com a inclusão da casca foi $15,2 \%$ maior do que a do tratamento sem a casca (0CS).

Grigsby et al. (1992) verificaram efeito linear crescente na digestibilidade aparente da FDN no trato digestório total de novilhos de corte, quando incluíram

Tabela 4. Consumo e digestibilidade aparente no trato digestório total (DATT) da matéria seca, da matéria orgânica, da fibra em detergente neutro, da fibra em detergente ácido e da hemicelulose em ovinos.

\begin{tabular}{|c|c|c|c|c|c|c|c|}
\hline \multirow[t]{2}{*}{ Itens $^{(1)}$} & \multicolumn{4}{|c|}{ Tratamentos $^{(2)}$} & \multirow[t]{2}{*}{$\mathrm{EPM}^{(3)}$} & \multicolumn{2}{|c|}{$\mathrm{P}^{(4)}$} \\
\hline & $0 \mathrm{CS}$ & $12,5 \mathrm{CS}$ & $25 \mathrm{CS}$ & $37,5 \mathrm{CS}$ & & Linear & Quadrático \\
\hline & \multicolumn{7}{|c|}{ Matéria seca } \\
\hline Consumo $\left(\mathrm{kg} \mathrm{dia}^{-1}\right)$ & 1,24 & 1,40 & 1,35 & 1,66 & 0,07 & 0,0192 & 0,4117 \\
\hline \multirow[t]{2}{*}{ DATT $(\%)$} & 72,52 & 75,88 & 76,83 & 77,40 & 1,30 & 0,0362 & 0,3222 \\
\hline & \multicolumn{7}{|c|}{ Matéria orgânica } \\
\hline Consumo $\left(\mathrm{kg} \mathrm{dia}^{-1}\right)$ & 1,15 & 1,31 & 1,27 & 1,57 & 0,07 & 0,0141 & 0,4171 \\
\hline CMOD $\left(\mathrm{kg} \mathrm{dia}^{-1}\right)$ & 0,85 & 1,00 & 0,97 & 1,23 & 0,06 & 0,0101 & 0,4988 \\
\hline \multirow[t]{2}{*}{ DATT $(\%)$} & 73,69 & 77,23 & 78,16 & 78,37 & 1,26 & 0,0376 & 0,2332 \\
\hline & \multicolumn{7}{|c|}{ Fibra em detergente neutro } \\
\hline Consumo $\left(\mathrm{kg} \mathrm{dia}^{-1}\right)$ & 0,50 & 0,61 & 0,66 & 0,75 & 0,04 & 0,0093 & 0,8626 \\
\hline CFDND $\left(\mathrm{kg} \mathrm{dia}^{-1}\right)$ & 0,31 & 0,42 & 0,47 & 0,54 & 0,04 & 0,0040 & 0,6572 \\
\hline \multirow[t]{2}{*}{ DATT $(\%)$} & 61,39 & 69,00 & 70,88 & 72,36 & 1,81 & 0,0136 & 0,1608 \\
\hline & \multicolumn{7}{|c|}{ Fibra em detergente ácido } \\
\hline Consumo $\left(\mathrm{kg} \mathrm{dia}^{-1}\right)$ & 0,25 & 0,33 & 0,36 & 0,39 & 0,02 & 0,0053 & 0,3162 \\
\hline CFDAD $\left(\mathrm{kg} \mathrm{dia}^{-1}\right)$ & 0,15 & 0,23 & 0,25 & 0,25 & 0,02 & 0,0173 & 0,0971 \\
\hline DATT $(\%)$ & 61,72 & 69,51 & 69,74 & 63,41 & 2,27 & 0,2061 & 0,0416 \\
\hline Consumo $\left(\mathrm{kg} \mathrm{dia}^{-1}\right)$ & 0,25 & 0,28 & 0,29 & 0,36 & 0,02 & 0,0046 & 0,2162 \\
\hline CHD (kg dia $\left.{ }^{-1}\right)$ & 0,16 & 0,19 & 0,22 & 0,31 & 0,02 & 0,0007 & 0,1655 \\
\hline DATT $(\%)$ & 61,04 & 68,37 & 72,30 & 82,19 & 1,93 & 0,0002 & 0,5301 \\
\hline
\end{tabular}

(1)CMSD: consumo de matéria seca digestível; CMOD: consumo de matéria orgânica digestível; CFDND: consumo de FDN digestível; CFDAD: consumo de FDA digestível; CHD: consumo de hemicelulose digestível. (2)0CS: sem inclusão de casca de soja; 12,5CS, 25CS e 37,5CS: 12,5, 25 e 37,5\% de inclusão de casca de soja, respectivamente. ${ }^{(3)}$ Erro-padrão da média. ${ }^{(4)}$ Probabilidade de efeito (linear ou quadrático) dos tratamentos sobre as variáveis. 
$0,15,30,45$ e $60 \%$ de casca de soja (na MS), em substituição ao feno de gramínea de baixa qualidade. Os autores concluíram que a casca de soja exerceu influência positiva na digestão da parede celular das forragens, pois nem o pH ruminal ou a concentração de amônia analisados decresceram suficientemente para inibir a degradação da fibra, quando a casca substituiu o feno.

Trater et al. (2001) adicionaram 10, 20 e 30\% (na MS) de feno de alfafa em dietas à base de casca de soja e encontraram efeito quadrático, na digestibilidade aparente da FDN, no trato digestório total de novilhas leiteiras, sendo que o maior valor encontrado foi na dieta com $10 \%$ de feno e $90 \%$ de casca de soja (70,5\% de digestibilidade). Silva et al. (2002) observaram aumento na digestibilidade aparente da FDN no trato digestório total de bovinos, quando a quantidade de casca de soja passou de 18 para $42 \%$ da MS da dieta, apresentando resultado semelhante à dieta $25 \mathrm{CS}$ deste trabalho $(71,3$ e 70,9\%, respectivamente).

Verificou-se efeito quadrático na digestibilidade da FDA $\left(y=-2,7721 x^{2}+15,299 x+49,396 ; R^{2}=0,64\right)$ (Tabela 4), com a inclusão da casca de soja, e as dietas $12,5 \mathrm{CS}$ e 25CS apresentaram os maiores valores de digestibilidade. A maior concentração de lignina do feno pode ter interferido negativamente na digestibilidade da celulose, mediante barreiras físicas que impedem o ataque microbiano, resultando na menor digestibilidade da FDA na dieta 0CS. A queda da digestibilidade da FDA na dieta 37,5CS pode estar associada ao tempo de retenção das partículas da dieta no rúmen, que não foi suficiente para permitir maior digestibilidade da fração mais lentamente digestível da FDA (celulose). A inclusão de casca de soja, como fonte de suplementação em dietas com alta proporção de forragens, aumentou a digestibilidade da FDA no trato digestório total de bovinos (Falkner et al., 1994; Royes et al., 2001).

A digestibilidade da hemicelulose aumentou linearmente $\left(y=6,737 x+54,133 ; R^{2}=0,80\right)$ com a inclusão da casca de soja na dieta (Tabela 4). Este aumento ocorreu, provavelmente, em razão do baixo teor de lignina na casca, quando comparada ao feno de gramínea (2,5 e $5,4 \%$, respectivamente) (National Research Council, 2001). A lignina é o principal componente responsável pela diminuição da digestão dos polissacarídeos da parede celular, pois forma ligações covalentes com a hemicelulose por meio da xilose e arabinose, dificultando o acesso das enzimas microbianas ao sítio de reação do substrato: a hemicelulose (Jung \& Vogel, 1986).
Royes et al. (2001) também notaram maior digestibilidade da hemicelulose no trato digestório total de bovinos, quando incluíram casca de soja em dietas contendo feno de gramínea.

Apesar da inclusão da casca de soja nas dietas ter apresentado incrementos na digestibilidade dos nutrientes, a fibra do feno utilizado neste trabalho foi de alta qualidade e também proporcionou bons resultados sem a presença de casca de soja: 72,52\% na DATT da MS e 61,72\% na DATT da FDA (Tabela 4).

\section{Conclusões}

1. A adição de casca de soja reduz o tempo de ingestão, ruminação e mastigação (em minutos por dia, minutos por grama de matéria seca e minutos por grama de FDN), mas não prejudica a digestibilidade aparente dos nutrientes no trato digestório total.

2. O uso de até $37,5 \%$ de casca de soja em substituição ao feno aumenta o consumo diário de matéria seca digestível e é benéfico ao desempenho de ovinos.

3. A avaliação do comportamento ingestivo, em intervalos de 10 ou 15 minutos, não compromete os resultados finais das atividades de ruminação e ingestão.

\section{Referências}

ABEL-CAINES, S.F.; GRANT, R.J.; HADDAD, S.G. Whole cottonseeds or a combination of soybeans and soybean hulls in the diets of lactating dairy cows. Journal of Dairy Science, v.80, p.13531357, 1997.

ARMENTANO, L.; PEREIRA, M. Measuring the effectiveness of fiber by animal response trials. Journal of Dairy Science, v.80, p.1416-1425, 1997.

ASSOCIATION OF OFFICIAL ANALYTICAL CHEMISTS. Official methods of analysis. $15^{\text {th }}$ ed. Arlington, 1990. v.1, 1117p.

FALKNER, D.B.; HUMMEL, D.; BUSKIRK, D.; BERGER, L.L.; PARRET, D.F.; CMARIK, G.F. Performance and nutrient metabolism by nursing calves supplemented whit limited or unlimited corn or soyhulls. Journal of Animal Science, v.72, p.470-477, 1994.

FIMBRES, H.; KAWAS, J.R.; HERNADEZ-VIDAL, J.F.; PICÓNRUBIO, C.D.; LU, C.D. Nutrient intake, digestibility, mastication and ruminal fermentation of lambs fed finishing ration with various forage levels. Small Ruminant Research, v.43, p.275-281, 2002.

FIRKINS, J.L. Effects of feeding nonforage fiber sources on site of fiber digestion. Journal of Dairy Science, v.80, p.1426-1437, 1997.

GARCÉS-YÉPEZ, P.; KUNKLE, W.E.; BATES, D.B.; MOORE, J.E.; THATCHER, W.W.; SOLLENBERGER, L.E. Effects of supplemental energy source and amount of forage intake and performance by steers and intake and diet digestibility by sheep. Journal of Animal Science, v.75, p.1918-1925, 1997. 
GOERING, H.K.; VAN SOEST, P.J. Forage fiber analysis (apparatus, reagents, procedures and some applications). Washington: Agricultural Research Service, 1970. 19p.

GRANT, R.J. Interactions among forages and nonforage fiber sources. Journal of Dairy Science, v.80, p.1438-1446, 1997.

GRIGSBY, K.N.; KERLEY, M.S.; PATERSON, J.A.; WEIGEL, J.C. Site and extent of nutrient digestion by steers fed a low-quality bromegrass hay diet with incremental levels of soybean hull substitution. Journal of Animal Science, v.70, p.1941-1949, 1992.

IPHARRAGUERRE, I.R.; CLARK, J.H. Soyhulls as an alternative feed for lactating dairy cows: a review. Journal of Dairy Science, v.86, p.1052-1073, 2003.

IPHARRAGUERRE, I.R.; SHABI, Z.; CLARK, J.H.; FREEMAN, D.E. Ruminal fermentation and nutrient digetion by dairy cows fed varying amounts of soyhulls as a replacement for corn grain. Journal of Dairy Science, v.85, p.2890-2904, 2002.

JUNG, H.G.; VOGEL, K.P. Influence of lignin on digestibility of forage cell wall material. Journal of Animal Science, v.62, p.17031712, 1986.

NAKAMURA, T.; OWEN, F.G. High amounts of soyhulls for pelleted concentrate diets. Journal of Dairy Science, v.72, p.988994, 1989.

NATIONAL RESEARCH COUNCIL. Nutrient requirements of dairy cattle. $7^{\text {th }}$ ed. Washington: National Academy Press, 2001. 381p.

RABELO, M.M.A. Efeitos de fontes e níveis de fibra íntegra, em dietas contendo bagaço de cana-de-açúcar tratado sob pressão e vapor, sobre a digestibilidade, desempenho e comportamento ingestivo de bovinos de corte. 2002. 61p. Dissertação (Mestrado) - Escola Superior de Agricultura Luiz de Queiroz, Piracicaba.

ROYES, J.B.; BROWN, W.F.; MARTIN, F.G.; BATES, D.B. Source and level of energy supplementation for yearling cattle fed ammoniated hay. Journal of Animal Science, v.79, p.1313-1321, 2001.

SAS INSTITUTE. (Cary, Estados Unidos). SAS user's guide: version 6.12. Cary, 1996. 943p.

SILVA, L.D.F.; EZEQUIEL, J.M.B.; AZEVEDO, P.S.; CATTELAN, J.W.; BARBOSA, J.C.; RESENDE, F.D.; CARMO, F.R.G. Digestão total e parcial de alguns componentes de dietas contendo diferentes níveis de casca de soja e fontes de nitrogênio, em bovinos. Revista Brasileira de Zootecnia, v.31, p.1258-1268, 2002.

SILVA, R.R.; SILVA, F.F. da; CARVALHO, G.G.P.; VELOSO, C.M.; FRANCO, I.L.; AGUIAR, M.S.M.A.; CHAVES, M.A.; CARDOSO, C.P.; SILVA, R.R. Avaliação do comportamento ingestivo de novilhas $3 / 4$ holandês $\mathrm{x}$ zebu alimentadas com silagem de capim-elefante acrescida de $10 \%$ de farelo de mandioca: aspectos metodológicos. Ciência Animal Brasileira, v.6, p.173-177, 2005.

TRATER, A.M.; TITGEMEYER, E.C.; LÖEST, C.A.; LAMBERT, B.D. Effects of supplemental alfalfa hay on the digestion of soybean hull-based diets by cattle. Journal of Animal Science, v.79, p.13461351, 2001.

VAN SOEST, P.J.; ROBERTSON, J.B.; LEWIS, B.A. Methods for dietary fiber, neutral detergent fiber, and nonstarch polysaccharides in relation to animal nutrition. Journal of Dairy Science, v.74, p.3583-3597, 1991.

WEIDNER, S.J.; GRANT, R.J. Altered ruminal consistency by high percentages of soybean hulls fed to lactating dairy cows. Journal of Dairy Science, v.77, p.522-532, 1994a.

WEIDNER, S.J.; GRANT, R.J. Soyhulls as a replacement for forage fiber in diets for lactating dairy cows. Journal of Dairy Science, v.77, p.513-521, 1994b.

ZERVAS, G.; FEGEROS, K.; KOYTSOTOLIS, K.; GOULAS, C.; MANTZIOS, A. Soy hulls as a replacement for maize in lactating dairy ewe diets with or without dietary fat supplements. Animal Feed Science and Technology, v.76, p.65-75, 1998. 